\title{
Habitat Suitability Analysis for Swamp Deer (Rucervus Duvaucelii) Using Geo-Spatial Tools in Dudhwa National Park
}

\author{
Suneet Naithani ${ }^{1}$, Prachee Bedi ${ }^{1}$, Gopala Areendran ${ }^{2}$ \\ ${ }^{1}$ School of Environment and Natural Resources, Doon University, Dehradun, India \\ ${ }^{2}$ Indira Gandhi Conservation Monitoring Centre, World Wide Fund for Nature, New Delhi, India
}

Email address:

suneetnaithani@gmail.com (S. Naithani), pracheebedi02@gmail.com (P. Bedi), gareendran@wwfindia.net (G. Areendran)

To cite this article:

Suneet Naithani, Prachee Bedi, Gopala Areendran. Habitat Suitability Analysis for Swamp Deer (Rucervus Duvaucelii) Using Geo-Spatial Tools in Dudhwa National Park. American Journal of Remote Sensing. Vol. 6, No. 1, 2018, pp. 52-58.

doi: $10.11648 /$ j.ajrs.20180601.18

Received: May 15, 2018; Accepted: May 30, 2018; Published: July 7, 2018

\begin{abstract}
Dudhwa National Park (DNP), important conservation areas of India supporting the full range of threatened faunal and floral species. The Barasingha, swamp deer (Rucervus duvaucelii) considered as vulnerable, one of the flagship species. The satellite imagery of 1995, 2016 and 2017were used for Habitat Suitability Analysis (HSA) using multi-criteria analysis. The other primary and secondary data were also incorporated to generate habitat suitability model. Raster imageries of Landsat 5 and Landsat 8 were used to create various themes (variables) such as forest density, land use land cover, Normalized Difference Vegetation Index (NDVI), Normalized Difference Water Index (NDWI) along with topographic details. The result indicates that out of total geographical area approximately $2.000000-2.100000(20-21 \%)$ is highly suitable, $1.900000(19 \%)$ is appropriate, $1.800000(18 \%)$ moderately suitable, $1.700000(17 \%)$ less suitable and 1.500000-1.600000(15$16 \%$ ) area is least suitable. However, the study strongly advocates that the DNP is suitable landscape and grassland were noticed as one of the best habitat class for the conservation of swamp deer.
\end{abstract}

Keywords: Dudhwa National Park (DNP), Swamp Deer, Habitat Suitability Analysis (HAS),

Normalized Difference Vegetation Index (NDVI), Normalized Difference Water Index (NDWI)

\section{Introduction}

Habitat suitability mapping in wildlife management is an issue of global importance for the better management, conservation and protection of valuable species. In Dudhwa National Park (DNP), Swamp deer is also known as the Barasingha is a relatively large species of deer, usually seen in herds of 8-20 individual. They are crepuscular and live in the swampy grassland and floodplains of the Indian subcontinent and differ from all other species because antlers carry more than three times. Swamp deer are mainly grazers and listed as vulnerable $\mathrm{C} 1$ [1], the protection status is not secure. Thus, the species is assumed to still be in decline by $10 \%$ over 24 years mostly due to habitat degradation.

The swamp deer populations are threatened by poaching for antlers and meat. They have lost most of their former range because wetlands were converted and used for agriculture. The remaining habitat in protected areas is threatened by the change in river dynamics, increasing siltation and further degraded by anthropogenic pressures. Species are said to be a product of their habitat, and hence, maintenance of appropriate habitat is vital to wildlife management. A habitat is a place occupied by a specific population within a community population. Conventional surveys are always significant. Nevertheless, in many cases, tiresome fieldwork can be supplemented by Remote Sensing (RS) and Geographical Information System (GIS). Ground surveys have limitations whereas inaccessible areas with accuracy are possible through RS aided by limited ground survey [2-5]. RS and GIS procedures have been utilised widely in natural surroundings evaluation for different wildlife species.

A wildlife habitat suitability map depicts the suitability of vegetation, land and water for a specific wildlife species. To 
generate a habitat suitability model, species habitat information is required for analysis of a species in an integrated scientific manner. A quick appraisal of habitat and identification of potential sites has also been studied by [6]. Likewise, the territory of one-horned rhino (Rhinoceros unicornis) was studied [7]. In this study, the objectives were set to prepare the land-use and land cover map of the DNP along with themes of roads, settlement, water bodies with their buffer areas and to measure habitat suitability area of Swamp Deer. Debeljak [8] has studied the potential territories of a populace of red deer and its impact on the environment. GPS location of animal's presence and "binomial multiple logistic regression (BMLR)" techniques were integrated into a GIS environment for the HSI modelling [9]. Elephant habitat parameters using GIS, Remote Sensing was also analyzed by Aini et al. [10].

\section{Study Area}

The DNP is covering an area of $490.3 \mathrm{~km}^{2}$ lies from $28^{\circ} 18^{\prime} \mathrm{N}$ and $28^{\circ} 42^{\prime} \mathrm{N}$ latitude to $80^{\circ} 28^{\prime} \mathrm{E}$ to $80^{\circ} 57^{\prime} \mathrm{E}$ longitude. It supports a large number of endangered species. The DNP is bordering with Nepal having Mohana River in North and river Suheliis in South. The DNP has an extreme humid subtropical with dry winters type of climate. Monsoon from June to till September accounts for $90 \%$ of the rainfall of $150 \mathrm{~cm}$. Temperatures range from between a minimum of $9^{\circ} \mathrm{C}\left(48^{\circ} \mathrm{F}\right)$ in winter to a maximum of up to $45^{\circ} \mathrm{C}\left(113^{\circ} \mathrm{F}\right)$ in peak summer.

\section{Material and Methods}

ERDAS Imagine, Arc GIS, Google earth, topo-sheets and satellite images (Landsat 1995, 2016 and 1917 were required to generate the data set. For generating Land-use/ Land-cover (LULC), Landsat images were used for unsupervised classification, these classes were recorded into final classes.

The settlements, road network and water bodies themes with buffer have been created. For preparing Normalized Difference Vegetation Index (NDVI) and Normalized Difference Water Index (NDWI) the recent satellite data of 2016 and 1995 has been used for comparison. Iqbal et al. [11] has also studied the NDVI index in order to monitor vegetation cover changes during different time periods. Xu et al. [12] have also studied that NDVI of Landsat 7 and Landsat 8 is consistent when dealing with high vegetation covered areas (e.g. forest area and tall grass prairie) because the difference between Landsat 7 and 8 NDVI is close to zero when the value of NDVI is high. A different layer has been created for NDVI and for NDWI. Al the elements of theme were added for final map generation. Finally the weighted habitat suitability analysis was done as depicted in Figure 1.

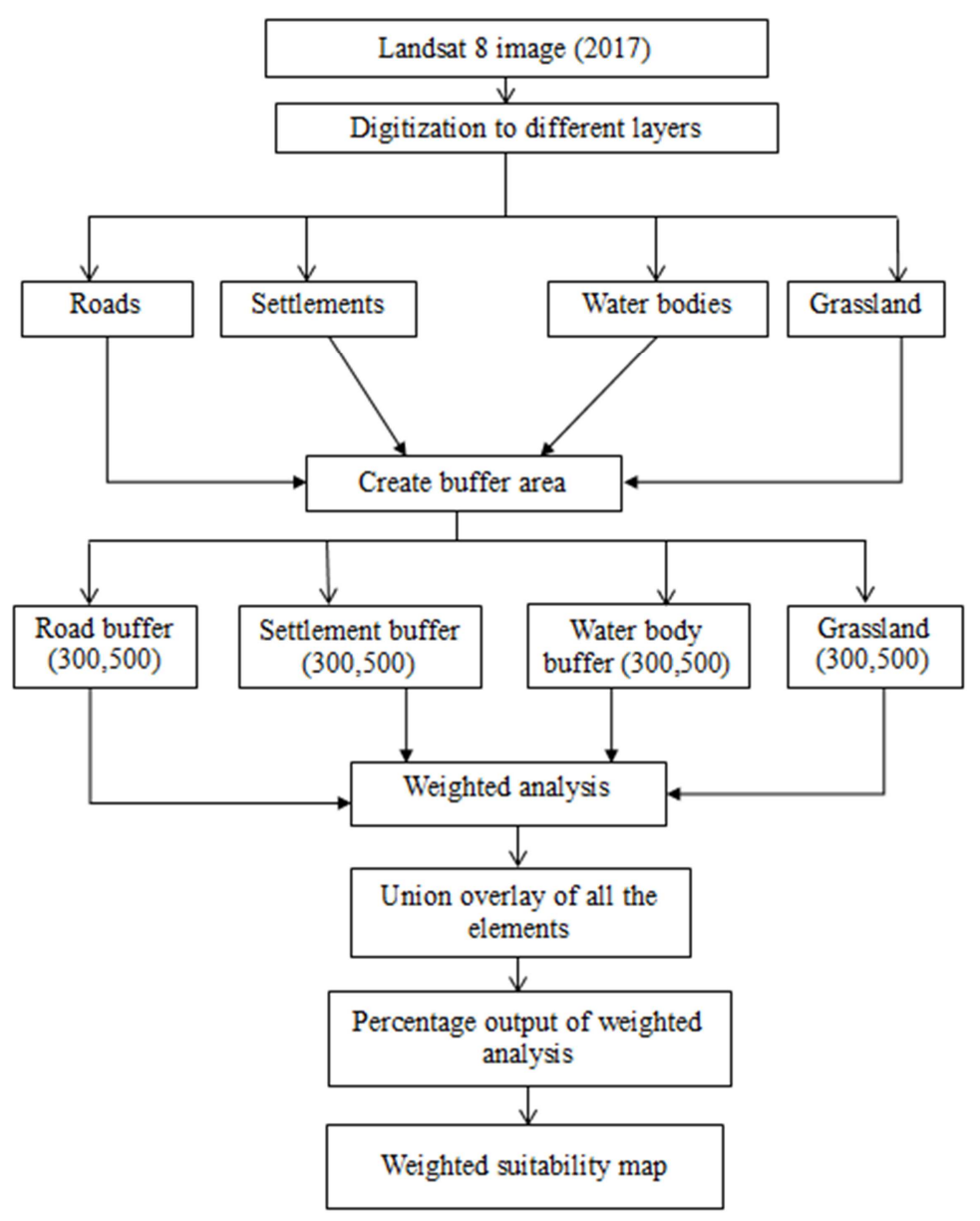

Figure 1. Methodology for Creating Weighted Habitat Suitability Analysis. 


\section{Results and Discussion}

The GIS and RS innovations demonstrated attainable for the habitat suitability mapping [13]. The LULC map of the DNP and the buffer area $(10 \mathrm{~km})$ were prepared assigning 47 classses (unsupervised clasification) and finally recoded into final 8 classes; forest, water bodies, grassland, swampy area, barren land, agriculture, settlement and sanddunes. Settlement and agricultural land depicted as land use classes. For creating themes of roads, settlements and water bodies of DNP, a 100 meter buffer was created to see the effect of the presence and declination of the animal species in DNP. The NDVI and NDWI maps were created to see the photosynthetic activity. NDVI is calculated on a per-pixel basis as the normalized difference between the red and near infrared bands from an image.

$$
\mathrm{NDVI}=\frac{(\mathrm{NIR}-\mathrm{RED})}{(\mathrm{NIR}+\mathrm{RED})}
$$

For Landsat 5 band values were:

$$
\mathrm{L} 5=\frac{(\text { band } 4-\text { band } 3)}{(\text { band } 4+\text { band } 3)}
$$

For Landsat 8 band values were:

$$
\text { L8 }=\frac{\text { (band } 5-\text { band } 4)}{(\text { band } 5+\text { band } 4)}
$$

Likewise the NDWI index is most appropriate for water body mapping. The NDWI can enhance the water information effectively in most cases. It is sensitive to builtup land and often results in over-estimated water bodies.

$$
\mathrm{NDWI}=\frac{(\mathrm{NIR}-\mathrm{GREEN})}{(\mathrm{NIR}+\mathrm{GREEN})}
$$

For Landsat 5 the band values were:

$$
\text { L5 }=\frac{(\text { band } 4-\text { band } 2)}{(\text { band } 4+\text { band } 2)}
$$

For Landsat 8 the band values were:

$$
\text { L8 }=\frac{(\text { band } 5-\text { band } 3)}{(\text { band } 5+\text { band } 3)}
$$

The maps were created for 1995 and 2016 to know about the difference and the effect on vegetation and water index, clearly affect the habitat suitability of the animal species. The elements roads, water bodies, settlement and grassland were used in GIS domain to see the dependency of species. Buruso, Thapa et al. and Tiwari el al. [14-16] have also studied the habitat suitability map was created using buffers of 300 and 500 meters.

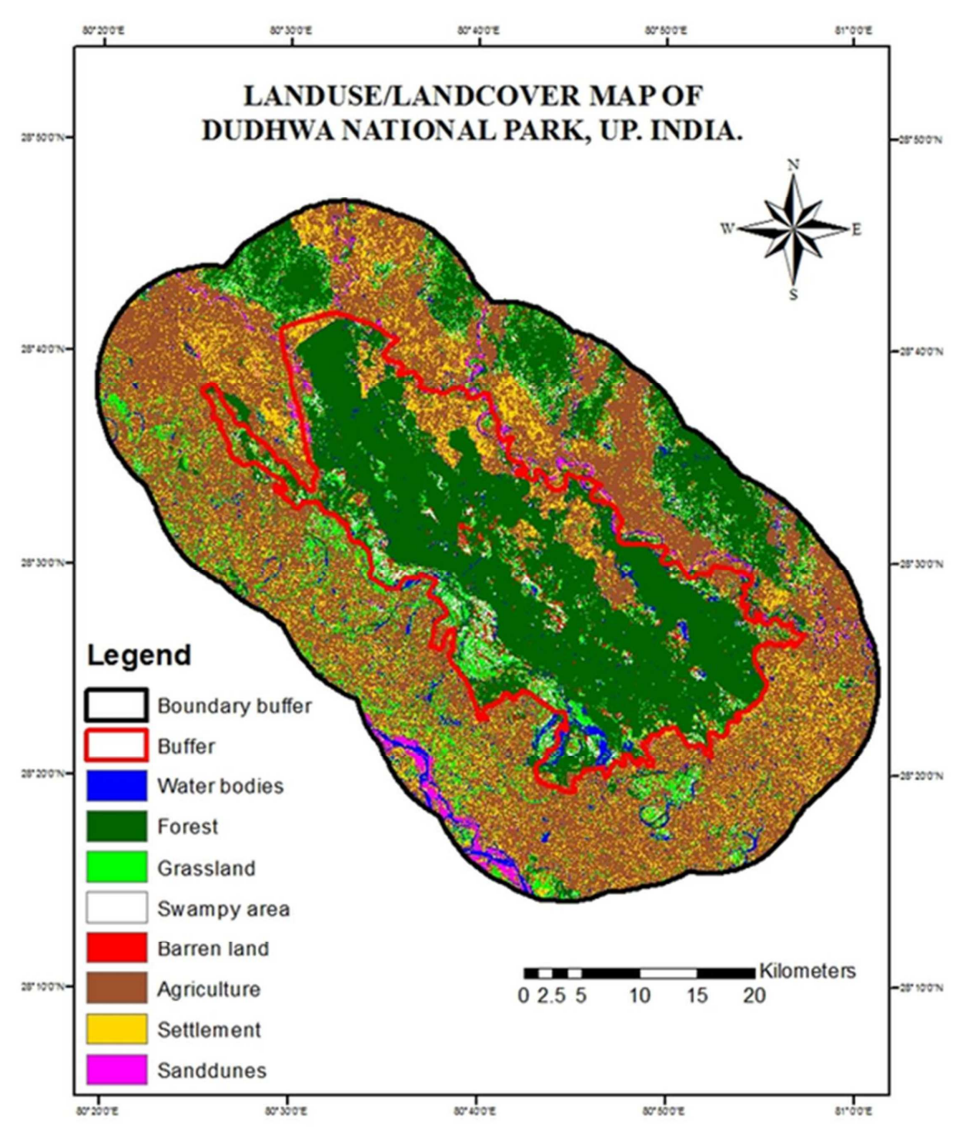

Figure 2. Land-use/ Land-cover of DNP. 


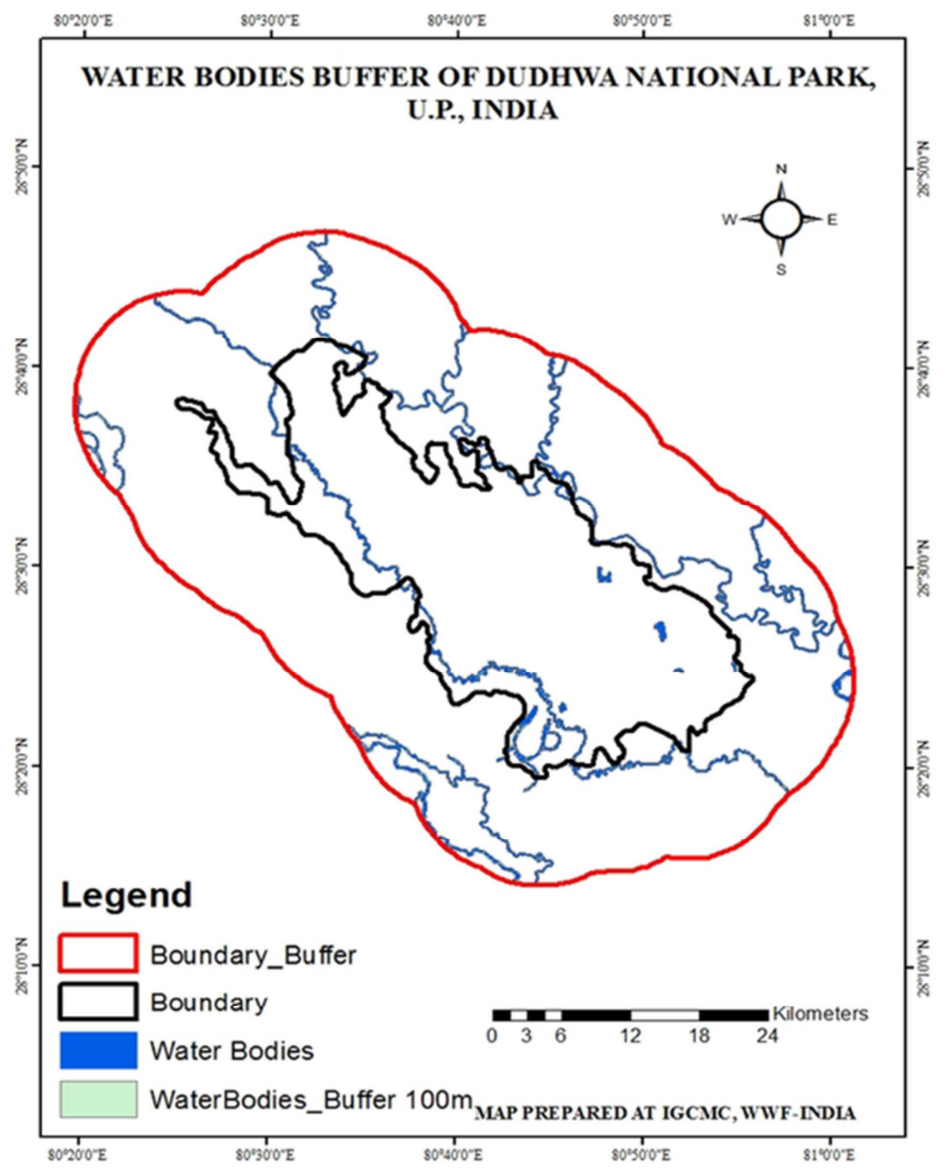

Figure 3. Water Bodies Buffer (100m), DNP.

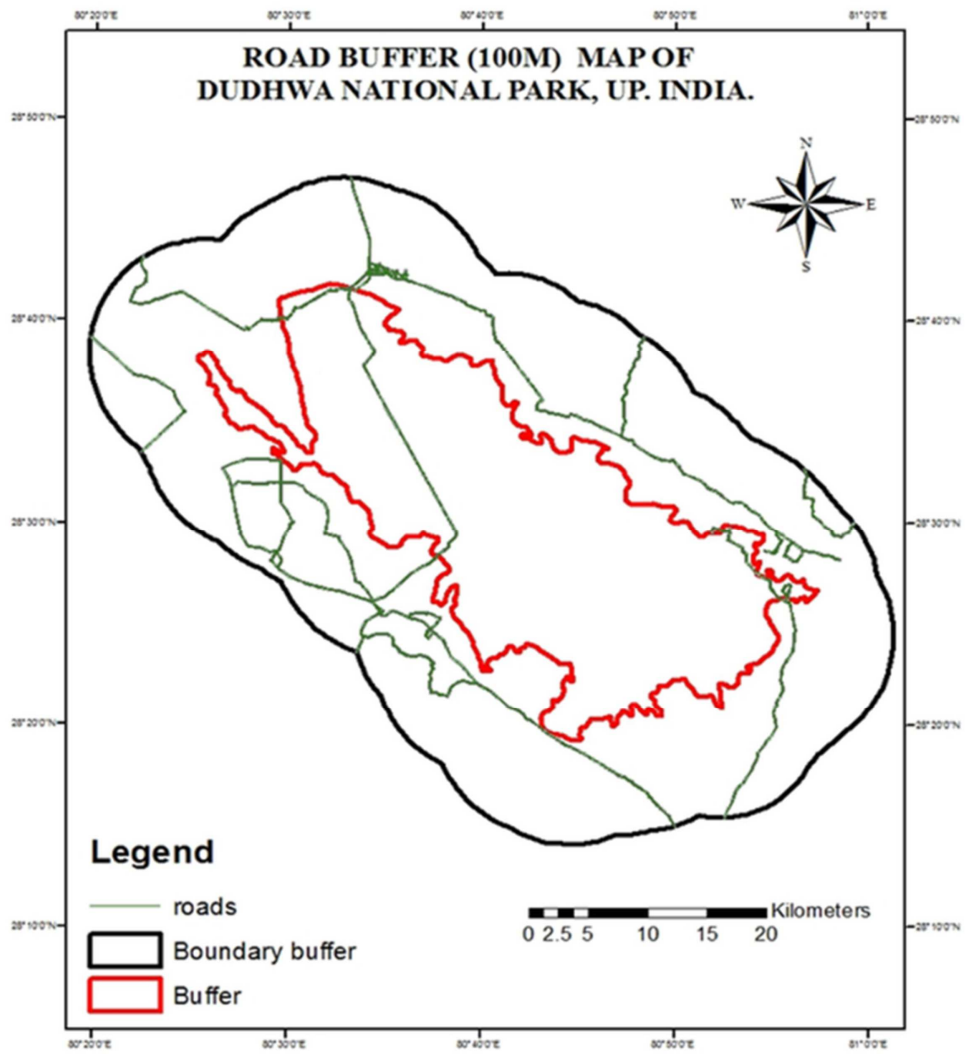

Figure 4. Road Buffer (100m), DNP. 


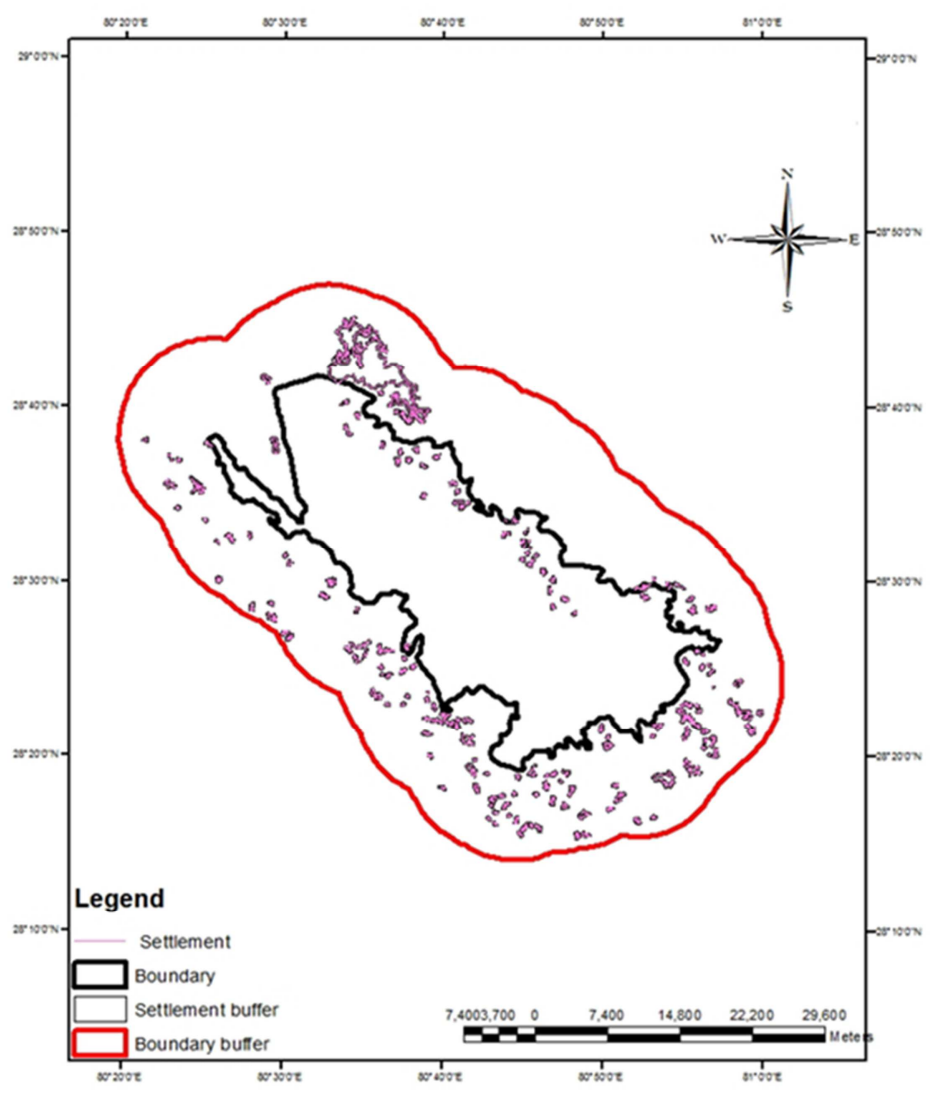

Figure 5. Settlement Buffer (100 m), DNP.

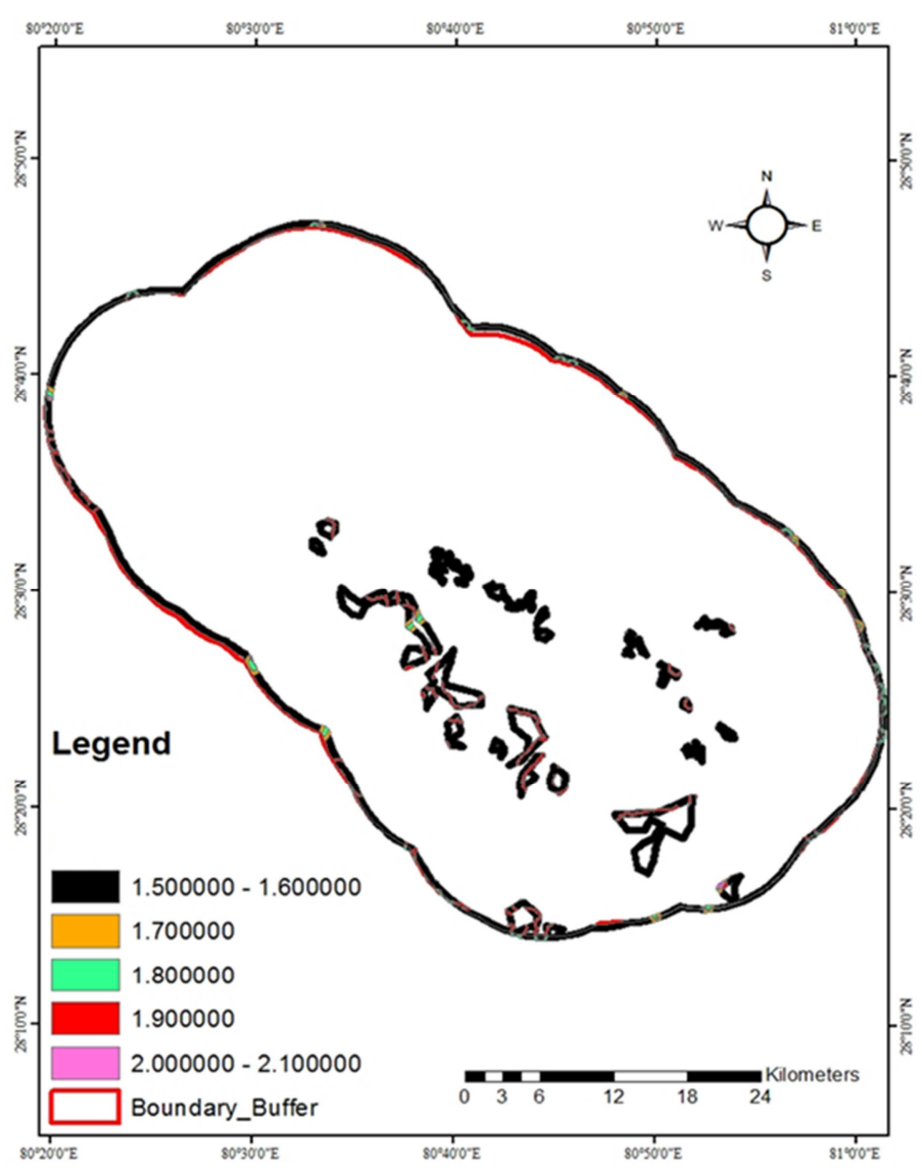

Figure 6. Habitat suitability, Swamp Deer, DNP. 
The variables used to calculate the habitat suitability of elephants were; vegetation cover (Figure 2), water bodies (Figure 3), roads (Figure 4), settlements (Figure 5) and habitat suitability map (Figure 6) is a scale over which habitat using various variables were evaluated. These were used to predict occurrence of the species by the environmental factors that can affect them. Habitat suitability was done by weightage given to them in the form of percentage.

Result indicates that out of total geographical area of the park approximately $2.000000-2.100000(20-21 \%)$ is highly suitable for the animal species, $1.900000(19 \%)$ is suitable, $1.800000(18 \%)$ moderately suitable, 1.700000 (17\%) less suitable and $1.500000-1.600000(15-16 \%)$ area is least suitable. The variables were weighted according to the suitability of swamp deer, which was $50 \%$ on grasslands, $30 \%$ on water bodies, $10 \%$ on roads and $10 \%$ on settlement of the area.

Habitat estimation of wild species in an area is fundamental to understand its demography and status and to plan for species management and conservation along with the area [17]. Several other workers have done the studies on habitat suitability models and analysis for different species in different protected and conservation areas [18-21]. Improvements can be done by effective efforts to conserve the grassland, forest and water bodies by park authorities with participatory approach in and around the DNP is needed to protect the food and feeding sites of Swamp deer (Rucervus duvaucelii).

\section{Conclusion}

The study revealed the potentiality of RS and GIS as tools for analyzing the habitat suitability. The elements; grasslands, water bodies, settlements and roads highly affect the swamp deer species in DNP. It was found that 2.0- 2.1 (20-21\%) areas is highly suitable for the Swamp deer. Comparing the NDVI and the NDWI data of two different years depicts a change in grassland and forest cover as well as water bodies declined to an extent due to environmental problems and human interventions will lead towards decline of the population of Swamp dear and their suitable habitat. There should also be quick responses towards illegal activities like hunting and poaching along with solution on human wildlife conflicts. The infant results can be used for the further study for the conservation of Swamp deer species as well as for the habitat conservation by wildlife managers.

\section{Acknowledgements}

We are sincerely thank to all those who have helped us throughout this study. We would like to thank Secretary General \& CEO, WWF-India and Programme Director, WWF-India, for allowing us to carry out our study. We also express our gratefulness to Dr. Krishna Raj, Mr. Mohit Sharma and Ms. Tanushree Mukherjee, WWF-India, Mr. Rajeev Kumar, Mr. Sandeep Kumar, ENVIS Centre, Mr.
Mayank Srivastava and Mr. Ranjeet Singh Bisht, WWF-India for their valuable information and guidance.

\section{References}

[1] Duckworth, J. W., et al., Rucervus duvaucelii. The IUCN Red List of Threatened Species 2015:e.

T4257A22167675.http://dx.doi.org/10.2305/IUCN.UK.20154. RLTS.T4257A22167675.en.15 May 2018

[2] Naithani, S., V. B. Mathur and C. Jeganathan, Habitat characterization of Western Tragopan (Tragopan melanocephalus), Great Himalayan national park, India. International Journal of Zoology Studies, 2018. 3(2): p. 46-53.

[3] Naithani, S., and V. B. Mathur, Musk Deer (Moschus chrysogaster) Habitat modeling in Great Himalayan national park conservation area. In: Naithani, S. and Jeganathan, C. (Eds.), Remote Sensing and GIS in Environmental Resource Management, Gaura Books India Pvt. Ltd, New Delhi, book. 2014. p. 69-82.

[4] Areendran, G., et al., Geospatial modeling to assess elephant habitat suitability and corridors in northern Chattisgarh, India. Tropical Ecology, 2011. 52(3): p. 275-283.

[5] Kushwaha, S. P. S., and P. S. Roy., Geospatial technology for wildlife habitat evaluation. Tropical Ecology, 2002. 43(1): p. 137-150.

[6] Nandy, S., S. P. S. Kushwaha and P. Gaur, Identification of Swamp Deer (Cervus duvauceli duvauceli Cuvier) potential habitat in Jhilmil Jheel Conservation Reserve, Uttarakhand, India using multi-criteria analysis. Environmental Management, 2012. 49(4): p. 902-14.

[7] Sarma, P. K., et al., Evaluation of habitat suitability for Rhino (Rhinoceros unicornis) in Orang National Park using Geospatial tools. ISRN Ecology, 2011. 2011: p. 9.

[8] Debeljak, M., et al., Habitat suitability modeling for Red Deer (Cervus elaphus L.) in South-central Slovenia with classification trees. Ecological Modeling, 2001. 138: p. 321330 .

[9] Imam, E., and S. P. S. Kushwaha, Habitat suitability modeling for Gaur (Bosgaurus) using multiple logistic regression, remote sensing and GIS. Journal of Applied Animal Research, 2013. 41(2); p. 189-199.

[10] Aini, S., Sood, A. M. and S. Saaban, Analyzing elephant habitat parameters using GIS, Remote Sensing and analytic hierarchy process in Peninsula Malaysia. Pertanika J. Sci. \&Technol, 2015. 23 (1): p. 37-50.

[11] Iqbal, M. Z., and M. J. Iqbal, Land use detection using Remote Sensing and GIS (acase study of Rawalpindi division). American Journal of Remote Sensing, 2018. 6 (1): p. 39-51.

[12] Xu, D., and X. Guo, Compare NDVI Extracted from Landsat 8 imagery with that from Landsat 7 imagery. American Journal of Remote Sensing, 2014. 2 (2): p. 10-14.

[13] Sanare, J. E., E. S. Ganawa and A. M. S. Abdelrahim, Wildlife habitat suitability analysis at Serengeti National Park (SNP), Tanzania case study Loxodonta sp. Journal of Ecosys Ecograph, 2015. 5: p. 164. 
[14] Buruso, F. H., Habitat suitability analysis for hippopotamus (H. amphibious) using GIS and remote sensing in Lake Tana and its environs, Ethiopia. Environmental Systems Research, 2018. 6:p 6.

[15] Thapa, V., M. F. Acevedo and K. P. Limbu, An analysis of the habitat of the Greater One-horned Rhinoceros Rhinoceros unicornis (Mammalia: Perissodactyla: Rhinocerotidae) at the Chitwan National Park, Nepal. Journal of Threatened Taxa, 2014. 6(10): p. 6313-6325.

[16] Tiwari, R., and G. S. Rawat, Assessment of Swamp Deer habitat in and Around Jhilmil Jheel conservation reserve, Haridwar, Uttarakhand, India. International Journal of Conservation Science, 2013. 4: p. 243-249.

[17] Varman, S. K., and R. Sukumar, The line transects method for estimating densities of large mammals in a tropical deciduous forest: An evaluation of models and field experiments. Journal of Biosciences, 1995. 20 (2): p. 273-287.
[18] Kumar, P., P. M. Hais and P. Kindlmann, Habitat suitability models of mountain ungulates, identifying potential areas for conservation. Zoological Studies, 2015. p. 54:37.

[19] Thapa, T. B., Habitat Suitability Evaluation for Leopard Using Remote Sensing and GIS in and Around Chitwan National Park, Nepal. Ph. D. thesis, Saurashtra University, 2011. p. 1223.

[20] Sampson, A. M., A habitat suitability analysis for cougar (Puma concolor) in Minnesota. Retrieved, the University of Minnesota Digital Conservancy, 2013. http:/hdl.handle.net/11299/162392

[21] Morrigan, E., Habitat Suitability Analysis of the Coast Horned Lizard (Phrynosoma coronatum Blainvillii) in the Santa Monica Mountain National Recreation Area. Book, https://books.google.co.in/books?id=DzC2ngEACAAJ, 2013. p. 112. 